James A.E. Mulroney

\title{
The Translation Style of Old Greek Habakkuk
}

\author{
Methodological Advancement in Interpretative Studies of the Septuagint
}

[Der Übersetzungsstil des altgriechischen Habakuk. Methodologischer Fortschritt bei Septuaginta-Interpretationen.]

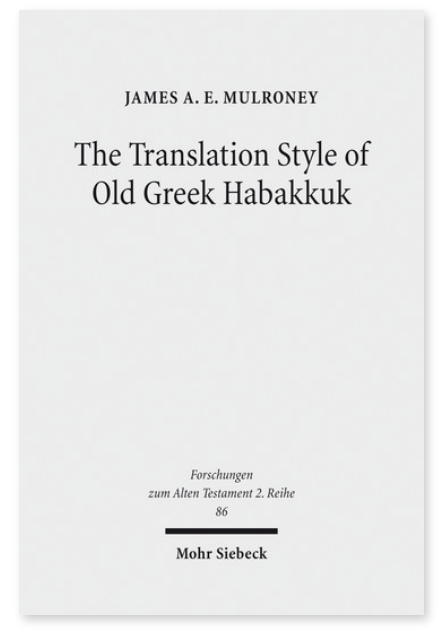

2016. XVII, 264 Seiten. FAT II 86

ISBN 978-3-16-154387-6

DOI 10.1628/978-3-16-154387-6

eBook PDF 94,00€

ISBN 978-3-16-154386-9

fadengeheftete Broschur 94,00€
Veröffentlicht auf Englisch.

James A. E. Mulroney erläutert die griechische Form des altgriechischen (Septuaginta) Buch Habakuk. Frühere Studien haben ein interlineares Modell angewendet und den hebräischen und griechischen Text in Einklang gebracht; diese Untersuchung untersucht den griechischen Text für sich selbst. Der erste wichtige Punkt hierbei ist der Begriff der Transformation in der Linguistik/Übersetzungswissenschaft: Jede Übersetzung erfordert Interpretation. Demnach ist der altgriechische Text eine Interpretation der hebräischen Grundlage. Der Autor bietet eine ausführliche Analyse der aktuellen methodologischen Probleme bei der Erforschung der Septuaginta. Diese Studie zeigt, dass der Übersetzer keiner wörtlichen Übertragungsweise im Allgemeinen folgte, sondern in einer Tradition des Lesens stand, die sich beispielhaft in subtilen theologischen Details des Buchs zeigt. Der persönliche Stil des Übersetzers zeigt sich in seiner Verwendung griechischer Rhetorik, während die meisten textuellen Besonderheiten seine Gewohnheit, Hebräisch und Griechisch zu lesen, verdeutlichen.

James A.E. Mulroney Born 1977; 2010 MAR, 2011 ThM from Westminster Theological Seminary (Philadelphia); 2015 PhD from the University of Edinburgh; currently lecturer in Old Testament at London Theological Seminary.

Jetzt bestellen:

https://mohrsiebeck.com/buch/the-translation-style-of-old-greek-habakkuk-9783161543876?no_cache=1 order@mohrsiebeck.com

Telefon: +49 (0)7071-923-17

Telefax: $+49(0) 7071-51104$ 